\title{
Inteligência coletiva: um olhar sobre a produção de Pierre Lévy
}

\author{
Angela Halen Claro Bembem
}

\begin{abstract}
Universidade Estadual Paulista (UNESP), Faculdade de Filosofia e Ciências de Marília. Mestre pelo Programa de Pós-Graduação em Ciência da Informação
\end{abstract}

Plácida Leopoldina V. Amorim da Costa Santos

\begin{abstract}
Universidade Estadual Paulista (UNESP), Faculdade de Filosofia e Ciências de Marília. Livre Docente em Catalogação, Professora do Programa de Pós-Graduação em Ciência da Informação
\end{abstract}

A inteligência coletiva é tema interdisciplinar e tem sido explorado pelas mais diversas áreas do conhecimento. Como proposta totalmente ligada ao conceito de informação $e$ às tecnologias da informação $e$ comunicação, considera-se como pertinente a discussão do tema no escopo da Ciência da Informação. Para tanto, realizou-se um estudo descritivo e exploratório a partir da obra de Pierre Lévy, identificando os preceitos sobre inteligência coletiva, suas ambiências e implicações. A pesquisa é de cunho documental e se foca em determinar o estado da arte da produção sobre inteligência coletiva, verificando o que tem sido produzido por Pierre Lévy e por outros autores sobre o tema, a fim de apontar quais as possíveis intervenções da Ciência da Informação nos estudos acerca de inteligência coletiva. O estudo mostrou que no campo de Ciência da Informação existem poucas investigações de nível teórico sobre inteligência coletiva. Apesar disso, discussões sobre a representação e organização da inteligência coletiva em ambientes digitais têm sido recorrentes na atualidade, abrindo assim novos campos de aproximação entre a Ciência da Informação e a investigação conceitual e prática em inteligência coletiva.

Palavras-chave: Informação e tecnologia; Inteligência coletiva; Ciência da Informação. 


\section{Collective Intelligence: an overview on Pierre Lévy's production}

Collective intelligence is an interdisciplinary subject and it has been explored for many different knowledge areas. As a proposal totally tied to the concept of information and information technologies and communication, it is considered as relevant the discussion about the topic within the scope of Information Science. Therefore, a descriptive and exploratory study was carried out from Pierre Levy's work, identifying the precepts of collective intelligence and its ambiences and implications. The research is documental, focusing on determining the state of the art of the production about collective intelligence, verifying what was produced by Pierre Lévy and by other authors about the subject, in order to point out what possible interventions of Information Science on studies about collective intelligence. The research showed that that in the field of Information Science there is little research on the theoretical level about collective intelligence. Nevertheless, discussions about the representation and organization of collective intelligence in digital environments have been recurrent in the present, thus opening new fields of approach between Information Science and conceptual research and practice in collective intelligence.

Key-words: Information and technology; Collective intelligence; Information Science.

Recebido em 06.11.2012 Aceito em 02.07.2013

\section{Introdução}

Em Ciência da Informação, no campo da Informação e Tecnologia, há o propósito de se investigar temas relacionados à geração e transferência da informação nos ambientes tecnológicos, associando-os a métodos e instrumentos viabilizados pelas tecnologias da informação e da comunicação (TIC). Esse campo de estudo se propõe a investigar os mecanismos de otimização dos ambientes informacionais digitais, valendo-se dos novos paradigmas de espaço-tempo da informação. É nessa ambiência que se inserem os estudos dos aspectos sociais e culturais das tecnologias em informação, tais como: empoderamento informacional, inclusão infodigital e inteligência coletiva, sendo o último o objeto de investigação deste artigo. 
Tecnologia da informação, segundo Le Coadic (2004, p. 84), é o estudo científico das técnicas de informação - conjuntos de processos metódicos, os quais baseiam-se ou não "[...] em conhecimentos científicos, empregados na produção, tratamento, comunicação, uso e armazenamento de informações". Atualmente, é impossível não relacionar tais ações à proposta de inteligência coletiva.

Segundo Lévy (2003, p. 28), a inteligência coletiva é "[...] uma inteligência distribuída por toda parte, incessantemente valorizada, coordenada em tempo real, que resulta em uma mobilização efetiva das competências". Ela visa ao reconhecimento das habilidades que se distribuem nos individuos, a fim de coordená-las para serem usadas em prol da coletividade. A coordenação dos inteligentes coletivos ocorre com a utilização das tecnologias da informação e comunicação.

Nota-se que as questões referentes ao trabalho colaborativo estão presentes no contexto da Ciência da Informação. Essa temática pode ser observada nas modificações paradigmáticas que essa ciência atravessou. Le Coadic (2004) mostra que as mudanças de paradigmas implicaram em alterações no ciclo da informação, as quais interferiram de forma direta no tempo da produção da informação, no tempo da comunicação e no tempo do uso da informação. Se outrora as técnicas e práticas em informação eram baseadas no trabalho individual e o gerenciamento de informação ocorria em acervos tradicionais orientados aos gestores, no novo paradigma o trabalho torna-se coletivo, as informações são encaminhadas em fluxos e estão orientadas aos usuários.

O trabalho coletivo permitiu o desenvolvimento de redes, o intercâmbio de informações e novas formas de acesso, construção e compartilhamento de conhecimentos com o auxílio do computador.

Essas novas formas de construção cooperativa do conhecimento, coordenadas pelas tecnologias da informacão e comunicação, carecem de uma real atenção da Ciência da Informação, tento em vista que a área se preocupa com "[...] o estudo dos fluxos da informação desde sua criação até a sua utilização, e a sua transmissão ao receptor em uma variedade de formas, através de uma variedade de canais" (BARRETO, 2002, p. 23). Vê-se que as preocupações da área de Ciências da Informação, apontadas por Barreto (2002), e das Tecnologias da informação, destacadas por Le Coadic (2004) são diretamente influenciadas pelas práticas em inteligência coletiva.

Essas influências podem ser comprovadas na observação dos ambientes colaborativos da $W e b 2.0^{1}$, isso porque, como mostra Santos (2008), os processos de aprendizagem e os serviços de colaboração e cooperação implicam no envolvimento e no comprometimento de se fortalecer uma inteligência coletiva.

Nos ambientes colaborativos da Web 2.0, é possível ao próprio usuário colaborador fazer a representação de informações, por exemplo, pela atribuição de tags aos conteúdos. Além disso, nesses ambientes a

\footnotetext{
Entende-se como Web 2.0 a segunda geração dos serviços disponibilizados pela Internet, e tem como características principais a potencialização das formas de publicação, compartilhamento e organização das informações, e a ampliação dos espaços de promoção de interações entre os participantes (PRIMO, 2007).
} 
comunicação ocorre de todos para todos, a informação torna-se compartilhada e o armazenamento de informações ocorre em estoques de informação cada vez mais descentralizados.

Apesar de considerável presença da proposta de inteligência coletiva na contemporaneidade, as designações acerca da inteligência coletiva, suas características e proposições ainda não são muito claras no âmbito da Ciência da Informação, como, também, não são claras quais seriam as contribuições da área para a temática em questão.

Para tanto, optou-se pela análise exploratória e descritiva sobre o tema inteligência coletiva, com base nas proposições de Pierre Lévy. 0 estudo é de caráter bibliográfico e documental, o qual se pauta em realizar o estado da arte da inteligência coletiva. O material publicado por Pierre Lévy, em primeiro plano, e, também, o que outros autores relevantes produziram sobre o tema serão considerados como universo estudado. O intervalo de tempo para o recolhimento das informações sobre a produção acerca da inteligência coletiva é de 1994, data da publicação de "A inteligência coletiva: por uma antropologia do ciberespaço" - principal obra de Lévy sobre o tema, até o ano de 2011.

\section{A inteligência coletiva}

Para Lévy (2003), a inteligência coletiva é aquela que se distribui entre todos os indivíduos, que não está restrita para poucos privilegiados. O saber está na humanidade e todos os indivíduos podem oferecer conhecimento; não há ninguém que seja nulo nesse contexto. Por essa razão, o autor afirma que a inteligência coletiva deve ser incessantemente valorizada. Deve-se procurar encontrar o contexto em que o saber do indivíduo pode ser considerado valioso e importante para o desenvolvimento de um determinado grupo.

Os intelectuais coletivos só poderão se reunir em um mesmo ambiente a partir da mediação das tecnologias da informação e comunicação. Com tais tecnologias, os saberes dos indivíduos poderão estar em sinergia. A coordenação dos saberes pode ocorrer no ciberespaço, o qual não é apenas composto por tecnologias e instrumentos de infraestrutura, mas também é habitado pelos saberes e pelos indivíduos que os possuem (LÉVY, 2000). O ciberespaço permite que os indivíduos mantenham-se interligados independentemente do local geográfico em que se situam. Ele desterritorializa os saberes e funciona como suporte ao desenvolvimento da inteligência coletiva.

Quanto à mobilização efetiva das competências, Lévy (2003) mostra que um fator importante para que ela ocorra é conseguir identificar as competências dos sujeitos e compreendê-las em suas multiplicidades.

O projeto da inteligência coletiva, cunhado por Lévy, não é apenas uma proposta ligada à cognição, mas é um projeto global que pressupõe ações práticas que se destinem à mobilização das competências dos indivíduos e que busquem, de fato, a base e o objetivo da inteligência coletiva, que é o reconhecimento e o enriquecimento mútuo daqueles que se envolvem nessa proposta (LÉVY, 2003). 
No período em que Lévy publicou as primeiras reflexões acerca da inteligência coletiva, o mundo desvinculava-se de uma duradoura divisão ideológica. Os países e os indivíduos eram identificados por sua opção política. Eram socialistas ou capitalistas. Rompida essa segregação formal, os indivíduos viam suas identidades ruírem. Nesse contexto, compreendese a persistência de Lévy (2003) em ressaltar a importância de existirem outros caminhos de inserção dos indivíduos em comunidades que não sejam caracterizadas por identidades étnicas, nacionais ou religiosas.

O caminho apontado por Lévy (2003) é a construção do laço social baseado no saber. Para ele, "o núcleo da engenharia do laço social é a economia das qualidades humanas" (LÉVY, 2003, p. 32). O que reuniria os indivíduos não seria mais a pertença a um lugar ou a uma ideologia, mas, sim, as capacidades de compartilhamento dos saberes individuais, uma vez que as identidades passariam a ser identidades do saber (LÉVY, 2003).

O saber referido não é o saber científico, mas o saber coextensivo à vida, diretamente relacionado aos conceitos savoir-vivre ou vivre-savoir, que quer dizer saber viver e viver saber, respectivamente (LÉVY, 2003).

A inteligência coletiva visa a tornar o saber a base principal, a infraestrutura das relações humanas. Ela só poderá de fato ocorrer em um determinado espaço, o qual Lévy (2003) nomeia como Espaço do saber. Nesse, as relações humanas são baseadas na valorização dos sujeitos e de suas habilidades. Lévy (2003) aponta que esse espaço ainda é virtual. Todavia, levando em conta o contexto atual, consideramos que o Espaço do saber encontra-se em construção e que ainda não se efetiva em sua plenitude, como proposto por Lévy (2003). Diz-se que ele ainda está em construção, pois há tecnologias disponíveis para colocar os sujeitos em sinergia e efetivar de fato o Espaço do saber. Entretanto, a efetivação do Espaço do saber vai além dessas tecnologias, uma vez que requer mudanças nas esferas política, social e, principalmente, no plano educacional.

\section{0 estado da arte da produção sobre inteligência coletiva}

Publicações relevantes sobre o tema, tanto de autoria de Pierre Lévy, como de outros autores, dentre elas, monografias, artigos, conferências e entrevista, que datam de 1994 até 2011, foram consideradas para identificar a inteligência coletiva e o seu contexto.

Para a explicitação dos resultados da investigação, no quadro 1 é apresentada a descrição de monografias, artigos e conferências que tratam do tema inteligência coletiva e, no quadro 2, as entrevistas dadas por Pierre Lévy, nas quais se aborda o tema inteligência coletiva. 


\section{Quadro 1 - Publicações do período de 1994 a 2011 - monografias, artigos e conferências}

\begin{tabular}{|c|c|}
\hline Obra & Enfoque dado ao tema "inteligência coletiva" \\
\hline $\begin{array}{l}\text { LÉVY, P. A inteligência } \\
\text { coletiva: por uma } \\
\text { antropologia do ciberespaço. } \\
\text { 4.ed. São Paulo: Loyola, } \\
\text { 2003. }\end{array}$ & $\begin{array}{l}\text { Traz as principais diretrizes acerca do tema inteligência coletiva, analisando-o mediante as seguintes } \\
\text { ambiências: ética, economia, tecnologia, política e estética. Tais destaques situam-se na primeira parte do } \\
\text { livro denominada como "Engenharia do laço social". Essa é entendida como a arte de despertar coletivos } \\
\text { inteligentes e valorizar a multiplicidade das habilidades humanas. Traça também reflexões sobre os espaços } \\
\text { antropológicos, sendo eles a Terra, o Território, o Espaço das Mercadorias, e o Espaço do saber. A segunda } \\
\text { parte da obra denominada "O espaço do saber" cartografa esses espaços, tecendo suas relações e } \\
\text { aproximações. São definidas as noções de espaços antropológicos, e examinadas as questões referentes às } \\
\text { identidades nesses espaços. Além disso, são observados os aspectos de significação, de espaço e tempo, e } \\
\text { do conhecimento dentro dos referidos espaços antropológicos. As considerações do autor visam } \\
\text { proporcionar formas de uso das mudanças que se encaminham, bem como mostrar os obstáculos presentes e } \\
\text { direcionar à possíveis campos de exploração. }\end{array}$ \\
\hline $\begin{array}{l}\text { LÉVY, P. A Emergência do } \\
\text { Cyberspace e as mutações } \\
\text { culturais. Porto Alegre: } \\
\text { Festival Usina de Arte e } \\
\text { Cultura, 1994. . Disponível } \\
\text { em: } \\
<\text { http://caosmose.net/pierrele } \\
\text { vy/aemergen.html>. Acesso } \\
\text { em: } 26 \text { set. } 2012 \text {. Palestra }\end{array}$ & $\begin{array}{l}\text { Dentre as possibilidades advindas da emergência de uma nova inteligência - a inteligência coletiva - está o } \\
\text { encaminhamento à elevação da sensibilidade e da percepção devido às formas de cooperação e coordenação } \\
\text { dos saberes em tempo real. Os equipamentos que envolvem tais características são os que ajudam no } \\
\text { aprendizado e na aquisição de saberes. Com as redes pode-se pensar em equipamentos tecnológicos que } \\
\text { venham permitir que cada indivíduo tire proveito dessa inteligência. Lévy observa que na atualidade a } \\
\text { biblioteca tem se desterritorializado, tem voltado às origens, ao passo que o saber passa estar contido na } \\
\text { própria humanidade. As comunidades portadoras dos saberes se manifestam em um espaço virtual, no } \\
\text { ciberespaço. Mediante a isso, Lévy faz alguns apontamentos relativos à influência da inteligência coletiva } \\
\text { no campo político, como as possibilidades da existência de uma democracia em tempo real permitida pelo } \\
\text { que o autor chama de "novos instrumentos técnicos" - as novas tecnologias da informação. }\end{array}$ \\
\hline $\begin{array}{l}\text { LÉVY, P; AUTHIER, M. As } \\
\text { árvores de conhecimentos. } \\
\text { São Paulo: Escuta, } 1995 .\end{array}$ & $\begin{array}{l}\text { A inteligência coletiva é a base para a construção da Árvore do Conhecimento - uma representação gráfica } \\
\text { que possibilita a organização efetiva de uma comunidade baseada no saber. O foco da criação desse projeto } \\
\text { é fazer com seja aparente as identidades de cada individuo em uma comunidade, mostrando o saber coletivo } \\
\text { dessa comunidade. A Árvore do Conhecimento se estrutura mediante a valorização dos saberes dos } \\
\text { indivíduos, o que significa que ela trás a existência o objetivo principal da inteligência coletiva. }\end{array}$ \\
\hline $\begin{array}{l}\text { LÉVY, P. Pour l'intelligence } \\
\text { collective. Le Monde } \\
\text { Diplomatic, Paris, out. } \\
\text { 1995. Disponível em: } \\
\text { <http://www.monde- } \\
\text { diplomatique.fr/1995/10/LE } \\
\text { VY/1857>. Acesso em: } 26 \\
\text { set. 2012. }\end{array}$ & $\begin{array}{l}\text { É apresentado o contexto do projeto da inteligência coletiva, que é um inteligência variada, distribuída, } \\
\text { valorizada, e que está em sinergia. Esse projeta baseia-se no princípio de que todas sabem alguma coisa, e } \\
\text { promove o reconhecimento dos saberes já adquiridos pelos indivíduos. Ela não é apenas a fusão das } \\
\text { inteligências individuais, mas é revitalização das singularidades. A inteligência coletiva é associada ao } \\
\text { desenvolvimento da economia, e à possibilidade de renovação da democracia. Assim, a interligação dos } \\
\text { computadores pode ser considerada como um instrumento da inteligência coletiva. No ciberespaço, lugar } \\
\text { onde ocorrem tais interligações, não há preocupações em se separar transmissores e receptores de } \\
\text { informação como ocorre na mídia tradicional. Todos podem exercer as duas funções. Lévy destaca a } \\
\text { importância de se desenvolver um projeto civilizatório baseado na inteligência coletiva, o qual inclui o } \\
\text { desenvolvimento de laços sociais permitidos pela partilha do conhecimento, o reconhecimento e valorização } \\
\text { das singularidades, e a criação de uma democracia mais participativa. }\end{array}$ \\
\hline $\begin{array}{l}\text { LÉVY, P. O que é virtual? } \\
\text { São Paulo: Editora 34, } 1996 .\end{array}$ & $\begin{array}{l}\text { O processo de desintermediação, ou seja, a não necessidade de existência de profissionais que realizam a } \\
\text { mediação entre conteúdos informacionais e indivíduos, coloca a prova a sobrevivência de algumas } \\
\text { profissões, devido as possibilidade de acesso direto aos conteúdos disponíveis no ciberespaço. Observa-se a } \\
\text { necessidade de os profissionais que antes se preocupavam com a mediação de conteúdos tornarem-se } \\
\text { organizadores da inteligência coletiva, fornecendo auxílio à navegação. A obra também trata das redes de } \\
\text { computadores como a concretização do projeto de novas maneiras da inteligência coletiva que sejam } \\
\text { flexíveis e democráticas, e que se baseiem no respeito das individualidades. Define inteligência coletiva de } \\
\text { maneira sintética em relação à definição de "A inteligência coletiva: por uma antropologia do ciberespaço", } \\
\text { explicando-a como "[...] a inteligência distribuída em toda parte, continuamente valorizada e sinergizada em } \\
\text { tempo real" (LÉVY, 1996, p.96). Além disso, o autor aponta o ideal da inteligência coletiva, que "é } \\
\text { reconhecer que a diversidade das atividades humanas, sem nenhuma exclusão, pode e deve ser considerada, } \\
\text { tratada, vivida como "cultura' [...]" (LÉVY, 1996, p.120). Ao tratar da problemática da inteligência coletiva, } \\
\text { aponta que o questionamento não é apenas em relação à decisão de concordar ou não concordar com a } \\
\text { inteligência coletiva, mas sim em escolher entre suas diversas formas, já que as ações podem ser emergentes } \\
\text { ou impostas, que respeitam as individualidades ou que homogenizam, que valorizem e integrem as } \\
\text { diversidades, ou que as desqualifique. }\end{array}$ \\
\hline $\begin{array}{l}\text { LÉVY, P. A revolução } \\
\text { contemporânea em matéria } \\
\text { de comunicação. } \\
\text { FAMECOS, Porto Alegre, } \\
\text { n.9, dez. 1998. Disponível } \\
\text { em: < } \\
\text { http://revistaseletronicas.puc } \\
\text { rs.br/ojs/index.php/revistafa } \\
\text { mecos/article/viewFile/3009/ } \\
\text { 2287>. Acesso em: } 26 \text { set. } \\
2012\end{array}$ & $\begin{array}{l}\text { Trata sobre e o desenvolvimento da Internet e da digitalização da informação sobre uma perspectiva } \\
\text { histórica. O autor caracteriza a origem dos dispositivos de comunicação e suas implicações, como o } \\
\text { encurtamento de distâncias, que é uma das possibilidades oferecidas pela Internet. Destaca alguns problemas } \\
\text { políticos, econômicos, e sociais que ocorrem devido ao desenvolvimento do ciberespaço, e que a } \\
\text { interconexão, que é base para os processos de inteligência coletiva, vai de encontro aos sistemas } \\
\text { burocráticos. O desenvolvimento da coletividade não se constrói na ampliação de fronteira, mas na } \\
\text { habilidade de melhor as relações de forma qualitativa. Quanto à interconectividade permitida pelos } \\
\text { computadores, afirma que ela pode mensurar de forma precisa um potencial de inteligência coletiva. O } \\
\text { domínio das tecnologias intelectuais, as quais podem aumentar as capacidades cognitivas, fornece vantagens } \\
\text { significativas aos indivíduos e aos contextos que as empregarem de maneira adequada; favorece também o } \\
\text { desenvolvimento e manutenção das atividades e processos relacionados à inteligência coletiva, haja vista } \\
\text { que as tecnologias intelectuais podem exteriorizar parte das operações cognitivas dos indivíduos. Os } \\
\text { instrumentos de interconexão são condição necessária para os processos de inteligência coletiva, entretanto } \\
\text { não são suficientes. As características presentes no ciberespaço, como a comunicação "todos-todos" e o } \\
\text { endereçamento por centros de interesse, são favoráveis ao desenvolvimento da inteligência coletiva. }\end{array}$ \\
\hline $\begin{array}{l}\text { LÉVY, P. O universal sem } \\
\text { totalidade, } \quad \text { essência da }\end{array}$ & $\begin{array}{l}\text { expansão do ciberespaço torna o mundo menos totalizável. Essa capacidade de universalização do } \\
\text { erespaço tende a continuar indeterminada, uma vez que os nós que compõem essa rede têm reorganizado }\end{array}$ \\
\hline
\end{tabular}


cybercultura. Caosmose.
1998. Disponível em: <http://caosmose.net/pierrele vy/ouniversalsem.html>. Acesso em: 26 set. 2012

LÉVY, P. Cibercultura. 2.ed. São Paulo: Editora 34, 2000.

SILVA, L.O.L. A Internet: a geração de um novo espaço antropológico. Biblioteca On-line de Ciências da Comunicação. 1999. Disponível 1999.
em: http://www.bocc.ubi.pt/pag/s ilva-lidia-oliveira-Internetespaco-antropologico.pdf >. Acesso em: 12 jul.2012.

LÉVY, P. A Conexão Planetária: o mercado, o ciberespaço, a consciência. São Paulo: Editora 34, 2001.

LÉVY, P. As inteligências coletivas. São Paulo: SESC, 2002. Palestra. Disponível em:

em:<http://www.sescsp.org. br/sesc/hotsites/pierre_levy/ Conferencia.doc $>$. Acesso em: 5 nov. 2012. as conectividades globais. Essa construção sem ordenação prévia do ciberespaço é denominada como "universal sem totalidades". O desenvolvimento do ciberespaço terá um efeito tão radical para as comunidades como teve o surgimento da escrita. A escrita permitiu que uma informação fosse conhecida mesmo que seus autores estivessem distantes. Ou seja, a mensagem se distancia do contexto em que foi produzida. Essa universalização da mensagem prima apenas pela manutenção do sentido; ela não permite a criação de significados além dos já definidos pelos criadores da mensagem. Assim também é a mídia tradicional, que não possui meios de interação, e desconsidera os contextos individuais de interpretação. A interconexão mundial, que emerge do ciberespaço, permite uma nova universalização que se difere da ocorrida com o advento da escrita, pois não ocorre de maneira a restringir os sentidos das interpretações. $\mathrm{O}$ universal sem totalidades permite o acesso à inteligência coletiva, já que ele não contêm a impossibilidade de interação nem tão pouco o isolamento. O ciberespaço fornece condições de existir uma comunicação direta, coletiva, que se apoie na interação. O universal sem totalidades ocorre na fase da evolução humana denominada cibercultura. A principal função da cibercultura é estender os rizomas de significados, que são permitidos pela diversidade dos coletivos inteligentes que compõem o ciberespaço.

A obra é resultado de um relatório requerido pelo conselho da Europa, que é responsável pelas implicações culturais do desenvolvimento advindo das tecnologias informacionais e da comunicação em suporte digital. Dentro do contexto das alterações provocadas pelas tecnologias informacionais, a obra trata das novas manifestações artísticas, da relação estabelecida com o conhecimento, dos aspectos educacionais e da aprendizagem, da diversidade linguística e cultural e das questões de exclusão e desigualdade. Explana acerca do ciberespaço, e da cultura que nele se desenvolve, a cibercultura, a qual pode ser compreendida como as técnicas materiais e intelectuais, as atitudes, os pensamentos e valores que se desenvolvem conjuntamente no crescimento do ciberespaço. No ciberespaço se reúnem os instrumentos da inteligência coletiva; eles funcionam como suportes dessa. A inteligência coletiva é apresentada como um dos principais motores da cibercultura, e como remédio contra o ritmo desestabilizador e excludente da mudança técnica, já que ela possui um caráter aberto e participativo favorecendo a cibercultura. Todavia, a inteligência coletiva proposta pela cibercultura também acelera as modificações técnicas, por isso pode ser entendida também como veneno para àqueles que não participam desse contexto. O autor observa ainda alguns tipos de problemas que ocorrem no campo da inteligência coletiva. A inteligência coletiva também pode ser observada como uma maneira de produção da humanidade que atua favorecendo a rede digital universal. Ela se aplica em diversas ambiências diferentes: em empresas, escolas, ambientes regionais e também nos internacionais. É ressaltado que não há possibilidade de existência da inteligência coletiva sem que haja virtualização e desterritorialização das comunidades no ciberespaço, as quais são uma inteligência coletiva em potencial. A obra traz uma definição de inteligência coletiva semelhante à de "A inteligência coletiva: por uma antropologia do ciberespaço" de 1994, dizendo que ela é um inteligência múltipla, distribuída por todas as partes, valorizada incessantemente, colocada em tempo real em sinergia, e que tem por fim a mobilização das competências.

Apresenta as redes de serviços telemáticos como uma geradora de novos espaços de atuação e significação dos homens, as quais permitem a criação de novas identidades e novas práticas culturais. Trata da necessidade de se pensar criticamente nas transformações proporcionadas pela atuação da Internet, e aponta a razão crítica como instrumento mais adequado para a reflexão sobre tal realidade. Identifica as deficiências existentes no modelo de comunicação tradicional, que suscitam a necessita de existir um espaço alternativo que permita a construção de uma comunicação mais democrática. Acerca da territorialidade, aponta que a Internet veio a alterar esse conceito, uma vez que permite tanto o pensar sobre a existência de novo território que contenha os fluxos de informações, como também o repensar as questões das fronteiras geográficas que outrora dificultavam a comunicação. Apresentam-se reflexões sobre a questão da identidade dos indivíduos que atuam nos espaços antropológicos, e sobre a identidade desses espaços. Com isso, são traçados apontamentos acerca da memória privada e da memória social. Quanto aos espaços antropológicos, foca-se com maior precisão na formação do Espaço do saber, o qual tem a possibilidade de gerar uma inteligência coletiva. Se observa que o saber compartilhado e construído conjuntamente é componente para a elaboração do Espaço do saber. Dessa forma, finaliza ressaltando a necessidade de se repensar o desenvolvimento da humanidade mediante ao turbilhão de informações presentes no contexto atual.

Trata das tecnologias intelectuais como favorecedoras do desenvolvimento e manutenção da inteligência coletiva, e da capacidade de a inteligência coletiva gerar capital financeiro e de conhecimento. A apresenta também como a reunião de vidas reais, e a imbricação das ações e consciências humanas. Os que não se inserirem nas práticas de inteligência coletiva, segundo o texto, são entendidos como os que deixarão de participar da cidade planetária do futuro, e não poderão desempenhar um papel importante nesse novo mundo, já que a inteligência coletiva será um elemento preponderante na produção de riquezas. Percebe-se por isso, que na obra há uma aproximação entre as práticas de inteligência coletiva e a economia, mostrando como a inteligência coletiva pode atuar nos processos da economia.

Lévy observa o crescimento das pesquisas relacionando inteligência coletiva e Internet, bem como o número de pessoas interessadas no tema. A Internet é vista como uma das primeiras praticantes da inteligência coletiva, já que seu surgimento teve origem nas movimentações em prol da cooperação no mundo científico. Entretanto, relata que não é apenas a comunidade cientifica que pratica a inteligência coletiva, há também práticas da inteligência coletiva no âmbito dos negócios e na política. A inteligência coletiva é definida, num sentido mais simplificado, como a partilha das funções que compõem a cognição humana. À medida que essas funções são potencializadas pelos sistemas técnicos, elas podem ser melhor partilhadas. Apesar disso, Lévy ressalta que a inteligência coletiva não esta apenas relacionada à cognição, e que ela só ocorre a partir do equilíbrio entre a competição e a cooperação. Para Lévy, navegar na Internet seria mergulhar na inteligência coletiva da humanidade, a qual é capaz de se aperfeiçoar constantemente devido à linguagem, uma vez que essa permite a humanidade fazer questionamentos, contar histórias e dialogar. O questionamento demonstra a limitação humana, o contar histórias implica na formação de vínculos entre os indivíduos, e no diálogo tem-se a oportunidade de participar daquilo que é o interior do outro. Para Lévy, a inteligência coletiva só se desenvolve em três dimensões de significações - a inteligência técnica, o pensamento conceitual e o polo relacional. O aperfeiçoamento dos órgãos de comunicação implica na evolução da inteligência coletiva, uma vez que eles facilitam o desenvolvimento dessa inteligência. Afirma 


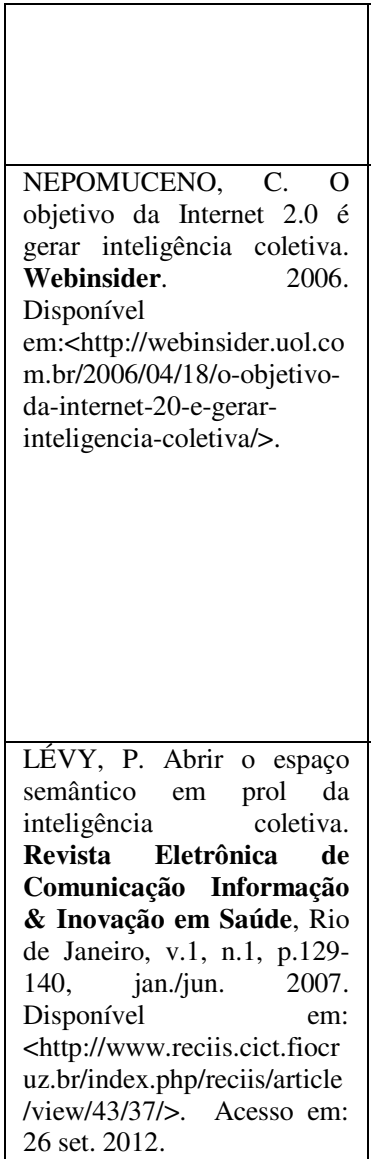

que devido à emergência do ciberespaço tem se aberto um novo campo de estudo, que é relacionado às pesquisas sobre inteligência coletiva humana. $\mathrm{O}$ autor prevê que em algum tempo a humanidade venha aprender a cultivar e criar ideias, almejando com isso que muitas outras pessoas se envolvam e se engajem no projeto da inteligência coletiva. Cabe destacar que nessa palestra o autor menciona o desenvolvimento de uma ciência da inteligência coletiva, e tal atributo, até então, não tinha sido observado em outros registros.

Trata das novas formas de comunicação e interação permitidas pela chamada Web 2.0. Dentre tais mudanças destaca o uso dos navegadores para a leitura de textos em formato não linear, as listas de discussão que permitem a comunicação colaborativa, e o correio eletrônico, que permitiu a troca de mensagens de forma rápida e barata. Mostra que a comunicação horizontal entre usuários da rede permitiu a criação e disseminação de novos produtos, e criação de projetos e empresas. O autor reconhece que a Internet é um importante meio de comunicação horizontal, que permite a interação a distância. Atenta ainda para a necessidade de preparar profissionais para o novo modelo comunicacional, que sejam aptos a administrar conflitos, proporcionar encontros e organizar a memória dos coletivos inteligentes, a fim de que essa seja recuperada de maneira eficiente. São reconhecidas as dificuldades existentes na instauração dos projetos de potencialização da Web 2.0, porque esses vão de encontro à cultura até então construída. Tais projetos para a geração da inteligência coletiva são de mudanças culturais, mediante a utilização de ferramentas de interação. $\mathrm{O}$ aceite mais rápido quanto a utilização dessas propostas será por parte dos oprimidos pelos modelos clássicos de comunicação, por aqueles que até então eram impotentes perante esses modelos. Dessa forma, entende-se que quanto mais canais de comunicação tradicional criarem impedimentos quanto a participação ativa dos indivíduos, mais haverá interesse em se desenvolver propostas relacionadas à Web 2.0 e à inteligência coletiva. A inteligência coletiva é definida como as decisões que são tomadas, a experiência que se adquire e a memória de determinado grupo que se preserva. Essa inteligência coletiva é o objetivo fundamental da Web 2.0.

Trata da necessidade de existir um sistema de coordenação, independente das linguagens naturais, que possa criar a possibilidade de relacionar semanticamente os conteúdos dispostos nos ambientes informacionais digitais. Para tanto, desenvolveu-se a Information Economy MetaLanguage (IEML) [Metalinguagem da Economia da Informação]. São apontados os obstáculos que não cooperam para que a memória dos coletivos inteligentes funcione de maneira adequada a permitir um gerenciamento em grau ótimo dos conhecimentos dispostos nos ambientes digitais. Dentre esse obstáculos, têm-se a diversidade de línguas naturais, a incompatibilidade dos sistemas de indexação e catalogação, e a variedade de ontologias, taxonomias, terminologias, sistemas de classificação e tesauros. Tais problemas, entendidos como de interoperabilidade semântica, impedem o desenvolvimento da inteligência coletiva que tenha como base as plataformas digitais. Assim, discorre-se sobre a estrutura e elementos da IEML. Esse sistema de coordenadas semânticas em âmbito universal permitiria a abertura para a utilização de ferramentas de pesquisas semânticas que sejam personalizadas, que atuem pautadas em conceitos e não em sequências de caracteres. A IEML existe também para ajudar a tomada de decisões no processo de gerenciamento do conhecimento. Com ela seria possível visualizar de forma cientifica a inteligência coletiva da humanidade. Destaca-se que a resolução das questões de interoperabilidade semântica, o oferecimento de um modelo que represente as diversidades conceituais e que ajude a tomada de decisões nos processos de gerenciamento do conhecimento, e a elaboração de uma ferramenta de observação de caráter cientifico que visualize os processos de inteligência coletiva devem ser dadas conjuntamente, uma vez que tais questões são inseparáveis. Lévy ainda aponta o crescimento das pesquisas e dos discursos teóricos acerca da inteligência coletiva nos últimos quinze anos (a considerar a data de publicação do artigo)

BRAGA, E.C. As redes sociais e suas propriedades emergentes como a inteligência coletiva. A criação do comum e da subjetividade. Revista Digital de Tecnologias Cognitivas, São Paulo, n.2, p. 48-59, jul./ dez. 2009. Disponível

em:<http://www.pucsp.br/po s/tidd/teccogs/artigos/pdf/tec cogs_n2_2009_artigo_braga pdf $>$. Acesso em: 26 set. 2012.

LÉVY, P. O futuro da investigação em redes sociais. Curitiba: Conferência internacional sobre redes sociais, 2010 Disponível em: $<$ http://escoladeredes.net/vid eo/pierre-levy-o-futuro-da1>. Acesso em: 26 set. 2012. Palestra.

SANTOS, H. N. Políticas culturais e inteligência
Se propõe a analisar a inteligência coletiva como uma característica que emerge das interações sociais permitidas pelas tecnologias digitais. As interações geradas entre os indivíduos pertencentes a um sistema de comunicação é entendida como inteligência coletiva, a qual é como um capital social, um bem produzido pelas interações sociais, como uma propriedade emergente. Discorre sobre algumas condições de possibilidade da emergência da inteligência coletiva, e observa ainda alguns mecanismos da Internet que se propõem a desenvolver uma inteligência coletiva. A inteligência coletiva e os trabalhos em rede são essenciais para o trabalho imaterial, o qual é aberto e liberto dos parâmetros rígidos dos antigos modelos de produção, e se ajusta mais à produção contemporânea. Esse tipo de trabalho gera novas subjetividades na sociedade. Assim, são necessários sistemas de informação que favoreçam as práticas de inteligência coletiva, que permitam a interação e comunicação "todos-todos". Com a emergência dessa inteligência coletiva novos bens imateriais são criados na sociedade, ou seja, são criadas relações sociais e modos de vida. Esse tipo de produção é entendida como "biopolítica". Por essa razão que o autor conclui que a emergência da inteligência coletiva altera as novas tecnologias, transformando-as em redes de comunicação biopolítica.

A evolução humana se deu a partir de habilidades que fizeram o homem se diferenciar dos animais, como a capacidade de construção de diálogos, a capacidade de contar histórias e organizar o pensamento e refletir. Por causa dessa questão evolutiva, a inteligência coletiva humana é mais desenvolvida que a inteligência coletiva dos animais. Quanto à compreensão das redes sociais, afirma ser impossível entendê-las sem antes compreender a comunicação humana. É destacada a necessidade de os indivíduos criarem os seus próprios critérios de seleção, para que seja possível construir os sentidos das informações disponíveis na rede. Para a criação da gestão do conhecimento pessoal, afirma que os indivíduos devem considerar as etapas: atenção ao ambiente, conexão com fontes valiosas, coleta e agregação de fluxos de dados, filtragem manual e automática, categorização dos conteúdos em tags, classes ou ontologias; gravação na memória a longo prazo, como por exemplo, na computação nas nuvens; síntese do conteúdo organizado, que pode ser em forma de um post em um blog, ou um verbete na Wikipedia; compartilhamento informacional em mídias sociais e a etapa da redefinição de prioridades. Lévy entende que a Internet ainda está em evolução, caminhando para uma etapa de compartilhamento semântico, na qual se poderá desenvolver uma linguagem universal não natural, ou seja, que não será falada por humanos, que poderá resolver a questão da padronização dos metadados na Internet.

Propõe uma aproximação entre políticas culturais e o conceito de inteligência coletiva. Destaca que apesar de o conceito ser amplamente utilizado no contexto da Web, a inteligência coletiva tem possibilitado uma 
coletiva. Contemporânea Rio de Janeiro, v. 9, n.1, p. 36-45, 2011. Disponível em: $<$ http://www.contemporanea. uerj.br/pdf/ed_17/contempor anea_n17_03_nepomuceno.p df $>$. Acesso em: 26 set. 2012.

Fonte: elaborado pelos autores. nova perspectiva para o contexto urbano e social, e que as possibilidades da Web se direcionam para a modificação do espaço social. Ressalta que a consciência social e a apropriação dos meios que favorecem o florescimento da inteligência coletiva permitem o aumento da participação dos atores sociais. Nesse contexto, a capacitação e o aprendizado coletivo atuam a favor de mudanças políticas. Há, portanto, uma mudança de cultura política iniciada pela sociedade que faz uso das potencialidades trazidas pela inteligência coletiva. Afirma que a noção de inteligência coletiva coloca todo o cidadão como indivíduo ativo, e que ao Estado cabe articular essa questão a fim de implantar políticas públicas culturais que levem em consideração a diversidade de sujeitos e suas contribuições. O sujeito passa a ser um sujeito coletivo que intervém na política e na estrutura social; suas ações são ampliadas pelas redes e veículos de comunicação, e os processos de cooperação tornam-se contínuos.

\section{Quadro 2 - Publicações do período de 2000 a 2009 - entrevistas dadas por Pierre Lévy}

\begin{tabular}{|c|c|}
\hline Obra & Enfoque dado ao tema "inteligência coletiva" \\
\hline $\begin{array}{l}\text { VERAS, E. Um "chat" com } \\
\text { Pierre Lévy. Agência RBS. } \\
\text { 2000. Disponível em: } \\
\text { <http://www.compsociedade } \\
\text {.hpg.ig.com.br/pierre/terra.ht } \\
\text { m>.>. Acesso em: } 15 \text { dez. } \\
\text { 2010. Entevista. }\end{array}$ & $\begin{array}{l}\text { Pierre Lévy afirma que os que têm acesso à Internet são aqueles que estão conectados à inteligência coletiva. } \\
\text { Afirma também que com o advento da imprensa os problemas de memória foram resolvidos, uma vez que a } \\
\text { humanidade passou a poder acumular conhecimento. Entretanto, hoje a participação ativa deixa de } \\
\text { concentrar-se em um número pequeno de privilegiados, passando a permitir que todas as pessoas participem } \\
\text { da inteligência coletiva. Para Lévy, quanto mais os sistemas de comunicação se desenvolvem, mais a } \\
\text { inteligência coletiva tem liberdade. }\end{array}$ \\
\hline $\begin{array}{l}\text { LÉVY, P. Pierre Lévy: } \\
\text { entrevista [jan. 2001]. } \\
\text { Entrevistadores: P. Murkun. } \\
\text { et al. São Paulo: TV Cultura, } \\
\text { 2001. Disponível em: } \\
\text { <http://www.rodaviva.fapesp } \\
\text {.br/materia/47/entrevistados/ } \\
\text { pierre_levy_2001.htm>. } \\
\text { Acesso em: } 5 \text { nov.2012 }\end{array}$ & $\begin{array}{l}\text { Lévy aponta que no futuro poderá haver menos miséria e pobreza, e isso permitirá que as pessoas participem } \\
\text { mais da inteligência coletiva. O mundo nesse futuro se organizará mais sob a forma de inteligência coletiva } \\
\text { do que sob os padrões tradicionais hierárquicos. Ao analisar as comunidades virtuais, afirma que a } \\
\text { sociabilidade passará mais por laços sociais, cujo embasamento não é mais do plano territorial, mas cada vez } \\
\text { mais são do plano dos processos de inteligência coletiva. }\end{array}$ \\
\hline $\begin{array}{l}\text { LOMBARD, P. Le futur } \\
\text { Web exprimera l'intelligence } \\
\text { collective de l'humanité. Le } \\
\text { Journal du Net, [S.1.], } 25 \\
\text { ago. 2003. Disponível em: } \\
\text { <http://www.journaldunet.co } \\
\text { m/itws/it_plevy.shtml>. } \\
\text { Acesso em: } 27 \text { set. } 2012 \text {. }\end{array}$ & $\begin{array}{l}\text { Lévy afirma que a Web semântica proclama a inteligência coletiva da humanidade, a qual é globalizada e } \\
\text { interligada no ciberespaço. O filósofo ainda discorre sobre três modalidades de cognição humana - o } \\
\text { conhecimento (representações), alimentação (competências), e vontade (intenção) -, e explica que sua } \\
\text { proposta de inteligência coletiva visa explicar a inter-relação prática dessas três modalidades. Ao ser } \\
\text { questionado quanto ao fato de a inteligência coletiva ser a Web, uma vez que essa permite uma nova } \\
\text { dimensão da comunicação devido ao fato de ser favorável à partilha de conhecimentos, Lévy afirma que a } \\
\text { inteligência coletiva existe desde sempre. Para Lévy, a inteligência coletiva está se desenvolvendo devido à } \\
\text { instituição das linguagens e técnicas. Por isso, a evolução cultural do homem pode ser entendida como um } \\
\text { processo de crescimento da inteligência coletiva, e o advento da Web pode ser mais uma etapa dessa } \\
\text { evolução. Ele identifica as alterações que a Web propôs, e afirma que demorará algumas gerações até que } \\
\text { tais mudanças advindas do seu desenvolvimento sejam compreendidas e exploradas a fim de se otimizar a } \\
\text { inteligência coletiva. Lévy é questionado sobre o relacionamento da inteligência coletiva com o mundo dos } \\
\text { negócios, e ele afirma que há uma estrita ligação entre a inteligência coletiva de uma empresa e seu } \\
\text { desempenho econômico. Em três anos, considerando a data da entrevista, Lévy teria desenvolvido uma } \\
\text { primeira versão de uma ferramenta open source de representação e simulação da inteligência coletiva. } \\
\text { Acerca da linguagem ideográfica que Lévy já havia criado, ele afirma que ela pode se tornar parceira na } \\
\text { gestão da inteligência coletiva. Ao ser indagado sobre a formação de uma comunidade em torno do conceito } \\
\text { de inteligência coletiva, Lévy afirma que seu objetivo é construir um campo de pesquisa e ensino centrado } \\
\text { na coordenação da diversidade, já que a inteligência coletiva é uma prática aberta e não restritiva. }\end{array}$ \\
\hline $\begin{array}{l}\text { MINUANO, C. Poder da } \\
\text { inteligência coletiva vai } \\
\text { aumentar, diz Pierre Lévy. } \\
\text { Folha de São Paulo, São } \\
\text { Paulo, } 3 \text { out. } 2009 . \\
\text { Disponível } \\
\text { <http://www1.folha.uol.com. } \\
\text { br/folha/informatica/ult124u } \\
\text { 632868.shtml>. Acesso em: } \\
27 \text { set. 2012. }\end{array}$ & $\begin{array}{l}\text { Lévy desacredita de que formas de restrição e controle terão êxito no futuro, uma vez que movimentos em } \\
\text { direção à interconexão e liberdade de criação têm se tornado mais fortes. Dessa forma, afirma que a } \\
\text { inteligência coletiva é a legítima plataforma do desenvolvimento dos indivíduos e da prosperidade } \\
\text { econômica. }\end{array}$ \\
\hline 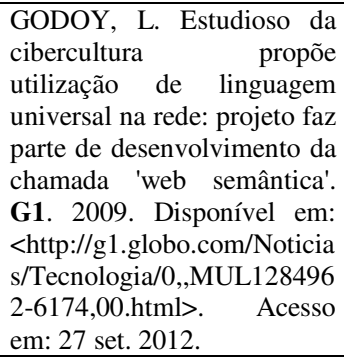 & $\begin{array}{l}\text { Lévy mostra que um dos objetivos do seu projeto do período, a Information Economy MetaLanguage } \\
\text { (IEML) [Metalinguagem da Economia da Informação], a longo prazo, é ajudar no inscrição da inteligência } \\
\text { coletiva no ciberespaço, ou seja, auxiliar as pessoas a terem o acesso à representação do que está sendo } \\
\text { tratado na Internet, e do que as pessoas estão querendo resolver. Lévy afirma que não era possível se obter } \\
\text { uma representação da inteligência coletiva, e que uma representação verdadeira é feita por um mapa } \\
\text { qualitativo que apresente o fluxo dos conceitos, dos assuntos, das idéias, e que mostre as relações semânticas } \\
\text { que estão sendo criadas pelas pessoas. Além disso, para Lévy quando o algoritmo de organização do Google } \\
\text { usa o "Pagerank", ele está considerando a inteligência coletiva. O Pagerank decide se um conteúdo é mais } \\
\text { importante que outro se possuir mais links levando ao conteúdo. Dessa forma o Google considera a } \\
\text { inteligência coletiva dos indivíduos que estão construindo a Web, mesmo que faça isso utilizando } \\
\text { parâmetros quantitativos. }\end{array}$ \\
\hline $\begin{array}{l}\text { NEPOMUCENO, C. Pierre } \\
\text { Lévy e a linguagem IEML. }\end{array}$ & $\begin{array}{l}\text { Lévy mostra novamente os objetivos da Information Economy MetaLanguage (IEML) [Metalinguagem da } \\
\text { Economia da Informação], sendo que um deles é resolver o problema de auto-referência da inteligência }\end{array}$ \\
\hline
\end{tabular}




\begin{tabular}{|l|l|}
\hline Webinsider-UOL. 2009. & coletiva. \\
Disponível $\quad$ em: & \\
<http://webinsider.uol.com.b & \\
r/2009/07/23/entrevista- & \\
pierre-levy-e-a-linguagem- & \\
ieml/>. Acesso em: 27. set. & \\
2012. & \\
\hline
\end{tabular}

Fonte: elaborado pelos autores.

Pode-se observar que o tema inteligência coletiva é tema interdisciplinar. Isso reflete uma das características da inteligência coletiva - o primor pela diversidade e valorização dessa.

Nota-se que as publicações da década de 90 discorrem de forma mais teórica sobre a inteligência coletiva e sobre seus temas adjacentes, como o desenvolvimento do ciberespaço e o surgimento da cibercultura. Atualmente, pode-se observar que as publicações direcionam-se às manifestações e implicações práticas da inteligência coletiva. Em sua maioria, tratam dos ambientes $W e b$, que possibilitam a interação e a criação colaborativa de conteúdos.

A fim de complementar a análise proposta, utilizamos a ferramenta Google Trends, que permite a verificação da incidência de buscas de um determinado termo, em um período de tempo. A ferramenta permite a verificação dos termos a partir de 2004. Analisamos o período de 2004 a 2011, considerando o termo inteligência coletiva nos idiomas português, inglês e francês, os quais levamos em conta para o levantamento do estado da arte sobre o tema.

O termo inteligência coletiva obteve máxima de volume de pesquisa nos anos de 2008, 2009 e 2010, sendo a maioria das buscas realizadas no Brasil. Já a maior incidência do termo collective intelligence ocorreu em 2006, 2007 e 2008. A frequência de busca do termo em inglês foi mais expressiva nos Estados Unidos e Reino Unido. Curiosamente - pelo fato de Pierre Lévy ser percursor do conceito e ter realizado importantes estudos na França e lecionado em universidades francesas -, o termo l'intelligence collective não apresentou volume de pesquisa suficiente para a exibição dos resultados. Os resultados obtidos pela utilização do Google Trends podem ser observados no Gráfico 1.

Gráfico 1 - Interesse das busca sobre inteligência coletiva com o passar do tempo

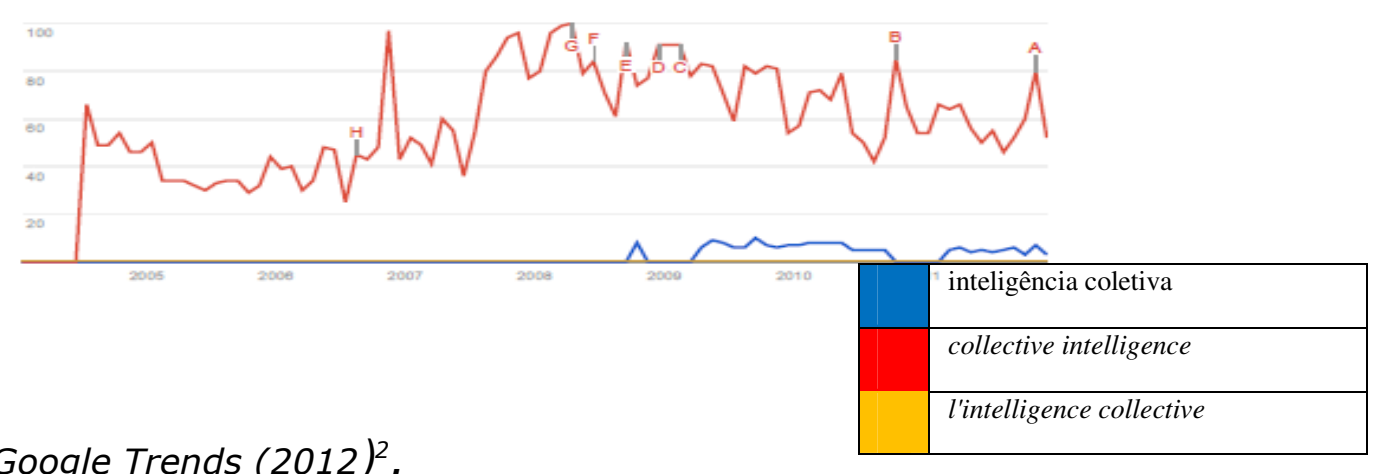

Fonte: Google Trends (2012) 2 .

2 Disponível em:<http://migre.me/aUblp>. Acesso em: 28 set. 2012. 
Os dados apresentados pelo Google Trends confirmam que a investigação acerca da proposta da inteligência coletiva foi, inicialmente, mais requerida no contexto internacional. O que confirma alguns aspectos detectados no levantamento do estado da arte, o qual mostrou certa resistência inicial dos pesquisadores brasileiros na aceitação das propostas de Pierre Lévy.

$\mathrm{Na}$ academia, inicialmente, havia resistência às considerações de Lévy; no contexto atual, em especial a partir de 2009, vê-se uma abertura da mídia às propostas de Lévy. Supõe-se que isso tenha ocorrido pelo fato de as tecnologias da informação e comunicação, principalmente as disponíveis na Web 2.0, como blogs, social bookmarking e wikis tornarem explícitas a proposta da inteligência coletiva, trazendo aplicações práticas para o que outrora ocorria apenas no plano teórico.

Além disso, notou-se, de forma clara, que a inteligência coletiva está totalmente associada a questionamentos nos planos social, político e econômico, o que confirma o exposto de Lévy (2003), ao considerar que a inteligência coletiva é uma proposta global e que vai além do plano cognitivo.

As publicações recentes de Pierre Lévy sobre a inteligência coletiva mostram sua preocupação em criar um mecanismo de coordenação, de caráter semântico, que independa das linguagens naturais e que seja capaz de relacionar os conteúdos presentes nos ambientes digitais. Isso demonstra uma evolução nos estudos relacionados à inteligência coletiva, uma vez que passam a ser visualizadas preocupações com 0 funcionamento da memória dos coletivos inteligentes nos ambientes digitais até então despercebidas. A atenção aos problemas de interoperabilidade semântica, mediante ao uso da Information Economy MetaLanguage (IEML) [Metalinguagem da Economia da Informação], poderá otimizar as práticas de inteligência coletiva e permitirá observar tais práticas de forma empírica (LÉVY, 2007).

No universo estudado, observou-se que não há estudos sobre inteligência coletiva na área de Ciência da Informação. Apesar disso, percebe-se que a representação da inteligência coletiva é uma das principais preocupações existentes na atualidade relacionadas ao tema. Além disso, temas como a desterritorialização dos acervos bibliográficos, democratização da informação e construção do conhecimento também estão incluídos na temática central.

\section{Considerações finais}

Ao analisar os aspectos da proposta da inteligência coletiva, percebeu-se que ela é uma forma de valorização das capacidades individuais, a qual se propõe a colocar em sinergia os indivíduos por meio da utilização das tecnologias, a fim de reuni-los para que compartilhem aquilo que de mais precioso possuem - a inteligência.

A organização de uma sociedade mais democrática e inclusiva, na qual as identidades dos indivíduos são construídas no saber, permitirá o encaminhamento a uma real democratização da informação. 
O levantamento do estado da arte das publicações sobre o tema inteligência coletiva permitiu observar que os aspectos teóricos do tema não são tão explorados pela área Ciência da Informação de uma forma geral. Supõe-se que isso ocorra pelo fato de a inteligência coletiva parte do campo de estudo de seu percussor, Pierre Lévy, que é a Filosofia.

Entretanto, a interdisciplinaridade presente na área de Ciência da Informação, a qual também busca, no campo da Filosofia, auxílio para as investigações acerca de assuntos como a epistemologia, também poderia se propor a buscar, na Filosofia, apoio para o início de uma discussão concreta acerca da construção da inteligência coletiva, tanto no que se refere a sua concepção quanto no que diz respeito ao seu desenvolvimento. Propõe-se que a conciliação entre as duas áreas seja mais que uma interdisciplinaridade, mas uma transdisciplinaridade, a qual pode favorecer a conexão das partes ao conjunto como um todo, sendo a investigação acerca do tema "ao mesmo tempo em todas as disciplinas, através das diferentes disciplinas e para além de qualquer disciplina", como aponta Nicolescu (2001, p. 2) citado por Santos e Vidotti (2009, p. 5).

Há a necessidade de um olhar mais atento a essa temática, uma vez que as práticas de inteligência coletiva têm influenciado de maneira considerável as formas de distribuição, acesso e construção do conhecimento em ambientes digitais.

Assim, a área de Ciência da Informação necessita discutir com maior profundidade os aspectos conceituais e práticos acerca da inteligência coletiva. A investigação teórica poderá auxilinar na implementação real dos princípios dessa proposta nos ambintes de colaboração em meio digital.

Quanto à prática em inteligência coletiva, a atual preocupação de Lévy é a representação e organização da inteligência coletiva nos ambientes digitais. Assim, consideramos campo propício à discussão em Ciência da Informação, haja vista que essa ciência e suas subáreas, em especial a Biblioteconomia, já têm como principais atividades a representação da informação e a organização da informação, tanto em ambientes tradicionais como, também, nos digitais.

Ainda no plano prático, acerca das questões de inserção dos sujeitos em propostas que visem ao aproveitamento da inteligência coletiva, consideramos que a maior inserção de indivíduos nos ambientes de colaboração em meio digital pode ocorrer pelo direcionamento dos esforços dos profissionais da informação no fornecimento de competências aos usuários colaboradores, para que esses tenham suas necessidades informacionais satisfeitas e alcancem autonomia nas atuações em rede. $E$ isso, de fato, poderá permitir a realização de um dos principais aspectos da inteligência coletiva - o encaminhamento a uma verdadeira democratização da informação. 


\section{Referências}

BARRETO, A. A. O tempo e o espaço da Ciência da Informação. Transinformação, Campinas, v. 14, n. 1, p. 17-24, jan./jun. 2002. Disponível em: $<$ http://repositorio.ibict.br/bitstream/123456789/179/1/BarretoTransinfor ma\%C3\%A7\%C3\%A302002.pdf>. Acesso em: 28 set. 2012

GOOGLE TRENDS. Resultado de pesquisa dos termos: inteligência coletiva, collective intelligence, l'intelligence collective. 2012. Disponível em: <http://migre.me/aUblp>. Acesso em: 28 set. 2012.

LE COADIC, Y. A Ciência da Informação. 2. ed. Brasília: Briquet de Lemos, 2004.

LÉVY, P. Abrir o espaço semântico em prol da inteligência coletiva. Revista Eletrônica de Comunicação Informação \& Inovação em Saúde, Rio de Janeiro, v. 1, n. 1, p. 129-140, jan./jun. 2007. Disponível em: <http://www.reciis.cict.fiocruz.br/index.php/reciis/article/view/43/37/>.

Acesso em: 11 out. 2012

LÉVY, P. A inteligência coletiva: por uma antropologia do ciberespaço. 4. ed. São Paulo: Loyola, 2003.

LÉVY, P. Cibercultura. 2. ed. São Paulo: Editora 34, 2000.

PRIMO, A. O aspecto relacional das interações na Web 2.0. E-Campos:

Revista da Associação Nacional dos Programas de Pós-Graduação em Comunicação, Brasília, v. 9, ago. 2007. Disponível em: <http://www.compos.org.br/seer/index.php/ecompos/article/view/153/154>. Acesso em: 11 out.2012

SANTOS, P. L.V. A. C. Redes informacionais como ambiente colaborativo e empoderamento: a catalogação em foco. In: GUIMARÃES, J. A. C.; FUJITA, M. S. L. (Orgs.). Ensino e Pesquisa em Biblioteconomia no Brasil: a emergência de um novo olhar. São Paulo: Cultura Acadêmica, 2008. p. 155-171.

SANTOS, P. L. V. A. C.; VIDOTTI, S. A. B. G. Perspectivismo e tecnologias de informação e comunicação: acréscimos à Ciência da Informação? DataGramaZero: revista de Ciência da Informação, Rio de Janeiro, v. 10, n. 3, jun. 2009. Disponível em: <http://dgz.org.br/jun09/Art_02.htm>. Acesso em: 11 out.2012. 